\title{
Explaining multistability: postphenomenology and affordances of technologies
}

\author{
Bas de Boer ${ }^{1}$ (I)
}

Received: 10 May 2021 / Accepted: 30 August 2021

(c) The Author(s) 2021

\begin{abstract}
A central issue in postphenomenology is how to explain the multistability of technologies: how can it be that specific technologies can be used for a wide variety of purposes (the "multi"), while not for all purposes (the "stability")? For example, a table can be used for the purpose of sleeping, having dinner at, or even for staging a fencing match, but not for baking a cake. One explanation offered in the literature is that the (material) design of a technology puts constraints on the purposes for which technologies can be used. In this paper, I argue that such an explanation—while partly correct—fails to address the role of the environment in which human beings operate in putting constraints on technology use. I suggest that James Gibson's affordance theory helps highlighting how stabilities in technology use arise in the interaction between human being and environment. Building on more recent approaches in affordance theory, I suggest that the environment can be conceptualized as a "rich landscape of affordances" that solicits certain actions, which are not just cued by the environment's material structure, but also by the normativity present in the form of life in which a human being participates. I briefly contrast the approach to affordances developed in this paper with how Klenk (2020) and Tollon (2021) have conceptualized the "affordance character" of technological artifacts, and highlight how a focus on the situated nature of affordances augments these earlier conceptualizations.
\end{abstract}

Keywords Postphenomenology $\cdot$ Affordances $\cdot$ Multistability $\cdot$ Philosophy of technology

\section{Introduction}

Recent work in the philosophy of technology has mobilized elements of affordance theory to explain why technological artifacts embody values (Tollon 2021; Klenk 2020). In doing so, such accounts attempt to prove the theoretical inadequacy of the "value-neutrality thesis" concerning technologies: the idea that technologies are mere instruments through which agents achieve the ends they have set more or less independently. At the same time, however, an affordance account shows that technologies cannot embody any value or affordance. In postphenomenology, one of the central theoretical approaches in the philosophy of technology, this feature of technologies is captured with the term multistability. The notion of multistability intends to capture the peculiar feature of technologies that they can be used

Bas de Boer

s.o.m.deboer@utwente.nl

1 Philosophy Section, University of Twente, Enschede, The Netherlands for a variety of purposes (the "multi"), but not for infinitely many (the "stability"). Indeed, it seems intuitive to say that a table can be used to have dinner, to sleep on, or to stage a fencing match-all dependent on the situation in which it is encountered. However, there are some purposes that a table cannot be used for, such as boiling water. And neither do we often use a table to write by using one of its table-legs as a kind of pencil.

But where does the multistability of technologies (e.g., tables) stem from? Is this a question to be answered empirically by developing an increasingly long list of different stable uses of particular technologies, or are there some general features of human-technology relations that might help answering this question? In this paper, I explore the latter option, and intend to develop a philosophical account of why technologies can be characterized as multi-stable, rather than "just" stable or "just" unstable. This account serves to address how the environment in which humans are embedded offers opportunities for and puts constraints on technology use. 
My paper proceeds in five steps: first, I discuss some postphenomenological accounts of multistability, and suggest that these generally fail to address the role of the environment in putting constraints on technology use. Second, I suggest that James Gibson's notion of "affordance" helps explaining how specific multistabilities arise, because it highlights that specific "ecological niches" put constraints on technology use. Third, I introduce the recent notions of "rich landscape of affordances" and "form of life" to argue that the normativities present in specific social practices put constraints on technology use. Fourth, I briefly contrast my approach with how Klenk (2020) and Tollon (2021) have conceptualized the "affordance character" of technological artifacts, and highlight how a focus on the situated nature of affordances augments these earlier conceptualizations, and helps accounting for multistability. In conclusion, I briefly elaborate how the approach to affordances developed in this paper might inform our understanding of the "disruptive" nature of new technologies.

\section{Postphenomenological accounts of multistability}

To get a clearer view on what exactly postphenomenologists take the multistability of technologies to be, let us start with a discussion of how the concept figures within postphenomenological studies. In a recent paper, Rosenberger defines the multistability of technologies as follows:

A technology can always be put to multiple purposes, can always fit in to multiple contexts, can always be meaningful in different ways to different people, can always evolve differently within different cultures [...]. At the same time $[. .$.$] any technology is always limited$ with regard to what it can mean and how it be may be used" (Rosenberger 2020a, 86).

From this definition it can be inferred that a technology can never be reduced to a particular usage (e.g., a hammer can be used for hammering nails, but also as a paper-weight), that particular uses are relative to particular socio-material contexts (e.g., a hammer fits both a workplace and a murder scene), and that the meaning particular people attach to a technology varies (e.g., a workman values a hammer differently than a murderer). However, the list of purposes for which a hammer can be used, the number of socio-material contexts in which it can function, and the ways in which it can be valued by individuals cannot be extended infinitely, hence it's multistability. But how can such stabilities be detected?

One of the key methods of postphenomenology is variational analysis. Inspired by Husserlian phenomenology, variational analysis searches to identify which stabilities are possible for a given technology. However, while "Husserl's use of variations aimed at producing invariants, or essences. Postphenomenology [...] finds multistabilities instead" (Ihde 2016, 85). As Robert Rosenberger puts it: "[P]ostphenomenology [...] eschews essentialism. Variational analysis reveals an object of study to be multistable" (Rosenberger $2020 \mathrm{~b}$, (3). The earliest examples of multistability in postphenomenology were given by Don Ihde. One concerns the multiple stable patterns that may appear when perceiving images. For example, a Necker Cube has two different threedimensional appearances, and can-as a two-dimensional figure-also appear as an insect with six legs in a six-sided cell of its web (Ihde 1990, 144-46). According to Ihde, these different variations are all equally stable patterns perceivable in the image encountered, of which we cannot say that one is more adequate than the other.

Another set of examples of multistability concerns how technologies function in practices. By giving examples from the history of archery, Ihde shows that there is no such thing as "the bow," but rather that bows are designed in a variety of ways relative to socio-cultural practices and habituated forms of embodiment, in each case inviting different usages (Ihde 2009, 16-18). Another example of multistability is how sardine cans left behind in New Guinea by Australian gold prospectors in the 1930s became valued as fashion objects by indigenous New Guineans that started to wear them on their forehead (Ihde 1990, 126), indicating that the stable use of a technology and the meaning that people attach to it also varies across cultures. Thus, on the hand, different stabilities that are relative to the perceiver can be discovered (as in the necker cube case), while on the other hand, one can discover different stabilities relative to the practice or culture in which a technology is taken up (as in the cases of archery and the way sardine cans were appropriated in New Guinea). This example indicates that technologies not only can be perceived differently, but also fit different meaningmaking practices. ${ }^{1}$ That is, depending on how technologies are appropriated - thereby attaining a particular stability, a particular form of intentionality is constituted. This makes any investigation of multistabilities a hermeneutical investigation, as it is concerned with identifying how different technologies and the different interpretations of them give rise to different interpretational frameworks (e.g., Ihde 1998, 48).

\footnotetext{
1 Also, the appropriation of technologies might give rise to novel interpretational frameworks. For example, Ihde often states that Galileo's use of the telescope was partly responsible for the constitution of a new (Modern) cosmology (e.g., Ihde 2016). In postphenomenological terms, it can be said that technologies mediate the concepts that people use to make sense of the world, as well as the norms that people orient to (e.g., de Boer 2021, 185). A critical discussion of the relation between the concept of "multistability" and that of "technological mediation" is beyond the scope of this paper.
} 
Such examples only illustrate the multistability of technologies abstractly, and offer no clear starting-point for conceptualizing how the multistability of technologies appears in concrete practices. Indeed, as Rosenberger notes, Ihde uses the notion of multistability primarily to criticize what he takes to be totalizing philosophies of technology that understand technology as having an invariable essence $(2020,87)$. However, more recent studies have analyzed in detail the different stabilities particular technologies allow for. For example, Rosenberger studied how public benches are designed in a way that makes them increasingly difficult to sleep on, inviting the dominant stability of sitting (2014), and also analyses the different stable uses of a bottle of glass, showing that it has a wide range of stable uses including being used for drinking to being used as a murder weapon, when it is smashed into smaller pieces before (2009). In such cases, the materiality of the technology is used as explanatory of why technologies enable certain uses, while making some other uses more likely or even impossible.

Other studies focus less on such material constraints but instead on how different practical concerns give rise to different stabilities. Forss showed how practitioners in a cytology laboratory have different stable ways of microscope use when observing cells, each giving rise to a different relation with the patient whose cells are observed (2012). Furthermore, Rosenfeld (2015) argued that the brain dead body allows for multiple stable interpretations, showing how the body can be perceived as a living body by family members that take breathing to be an indicator of life, while doctors related to it as a body in terms of organ donation. Aagaard (2018) shows how laptops can be used in a variety of stable ways in an educational setting, each having a different impact on the level of the attention laptop users pay to the lecture being given. Zheng (2021) suggested that the use of self-tracking applications not necessarily force users into stringent fitness regimes, but also allow for other stable uses that are not driven by self-discipline and self-surveillance. In such cases, not only the materiality of the design enables and constraints certain uses, but the use of a technology is relative to the practice or culture in which it is integrated (such that the microscope in the cytology laboratory is not imagined to be a murder weapon, for example).

The above - not exhaustive-list of postphenomenological analyses offers several examples of different instances of multistable technology use in a set of different contexts. However, these analysis tend not to reflect explicitly on what makes multistability possible, and what makes certain stabilities more likely than others. In a recent paper, Kyle Whyte tried to provide clarity on this matter by developing a theory of how the concept of multistability figures within postphenomenology $(2015,69)$. He distinguishes between two different ways in which multistability is brought to the fore: imaginative multistability and practical multistability.
Whyte describes imaginative multistability as an empirically testable hypothesis about how many stable patterns of the same object can be perceived and/or embodied from a first-person perspective (Ibid. 69). When this exercise is conducted, it becomes clear that there are no a priori reasons that one stable pattern is more adequate than the other. The results of such exercises (for example Ihde's variations on the Necker Cube, or Rosenberger's variations on for which purposes a bottle of glass can be used) can be communicated to others that can test these results themselves from their own first-person perspective.

Descriptions of practical multistability (e.g., the analyses by Forss, Rosenfeld, and Aagaard discussed above) lack the testability of their imaginative counterpart. They are better understood as ways of investigating from a thirdperson perspective the multistability of technologically mediated practices in order to shed light on how particular human-technology entanglements frame value frameworks. Such descriptions of technology use take place in a practical situation that analysts are not fully familiar with, such that they lack the relevant competences and sociocultural background to validate the adequacy of a certain form of stable technology use (Whyte 2015, 73). In the vocabulary of Don Ihde, we can say that such multistabilities are revealed from a perspective that has limited access to the different stabilities that might be constituted on a micro-level, because the analyst does not participate in the culturally situated macro-perception of the practitioners under study (Ihde 1990, 29). Whyte suggest that the forms of multistability revealed here do not serve solely for the purposes of discovering possible variations on a certain image or technology, but instead that the laying bare of a certain form of multistability is relative to the point of view the analyst that intends to reveal something specific about the practice she investigates (Whyte 2015, 75).

Whyte uses the concept of pivot to make clear how multistability must be understood in relation to the analyst's point of view. He writes that a pivot is that "which allows the variation to make sense as a variation" (Ibid. 75). When understanding multistability as the discovery of different variations of how an artifact can be used, experienced, or understood, we necessarily, so Whyte holds, isolate one element from its larger context. For example, when Rosenberger (2009) reveals the different stabilities for which a glass bottle is used, he uses the technological artifact as a pivot point, and is interested in varying on it to reveal for which different purposes it can be used across different practices. When studying laptop use in educational settings, Aagaard (2018) takes the educational setting itself as a pivot point, and uses different variations of laptop use to investigate their impact on the educational setting that is taken to be stable. 
Because descriptions of multistability are relative to the pivot point used by the analyst, Whyte urges postphenomenologists to be reflective about the taken pivot point (2015, 79). This is especially important, so Whyte notes, because the stipulated audiences of postphenomenological studies are practitioners whose practices have been studied from a postphenomenological view-"client communities" as Whyte calls them. Being able to effectively communicate the relevance of the multistabilities identified, and the consequences of limiting technology use to one particular or dominant stability, requires to be able to clearly identify and justify the pivot point(s) used. In Whyte's theory of multistability, the concept is understood as a methodological tool that might or might not allow communicating effectively to client communities how their practices can be improved.

With Whyte, we could indeed end with noting that dominant uses of technologies can be empirically observed, can be contrasted with non-dominant or non-existing uses, and can even be communicated to the practitioners under study for relevant purposes. In doing so, we would reduce multistability to a methodological issue that is entirely relative to the point of view taken by analysts, the specific things within a practice they intend to reveal, and the effects of how they communicate these to the practitioners that have been studied. ${ }^{2}$ However, such a way out does not yet explain why particular stabilities might be dominant in particular situations, and why multiple stabilities are possible. I use the next two sections to provide a starting-point for such an account that is explanatory of multistability: first, by linking James Gibson's affordance theory to the issue of multistability (3), and second by introducing the notions of "rich landscape of affordances" and "form of life" to argue that the normativities present in specific social practices put constraints on technology use (4).

\section{Affordances, niches, and places}

Recently, it was suggested that postphenomenologists-or the philosophy of technology more generally-focuses too much on individual human-technology relations, thereby neglecting how the environment is shaped by technological developments, as well as of how the environment shapes

\footnotetext{
$\overline{2}$ This seems to be the course taken in recent classification of multistabilities that distinguish between different multistabilities relative to the people that are detecting them and the practical purposes they might have in doing so (e.g., Rosenberger 2016; Wellner 2020). Another way of putting the main concern of this paper is that in contrast with such approaches that importantly differentiate between different epistemological usages of the term "multistability," in the present paper I am primarily concerned with the ontology of multistability.
}

how technologies are used, experienced, and understood (e.g., Aydin et al. 2019; Lemmens et al. 2016; Romele 2020). In this section, I introduce James Gibson's notions of "affordance," "ecological niche," "place," and Harry Heft's notion of "behavior setting" to address how specific environments constitute stability in technology use. As will become clear, these concepts offer a fruitful starting-point for understanding the stability of technology use beyond their material design by enabling to address how a specific environment might put constraints on the likelihood of e.g., a table being used for staging a fencing match, or for sleeping on.

According to Gibson, the primary things that an animal perceives in the environment are affordances, which can be understood as potentialities or solicitations for actions. In Gibson's words: "[t]he affordances of the environment are what it offers the animal, what it provides or furnishes, either for good or ill" [Gibson 2015 (1979), 119]. For example, if a certain substance is horizontal, flat, extended, and rigid, it affords support, it is the very floor that we are walking on. Other surfaces that offer support might be chairs that afford sitting, or desks that afford writing. What an animal perceives in the environment, then, are opportunities for action: floors are perceived as walk-able, chairs as sit-able, etc. According to Gibson, not only the physical environment, but also social and cultural phenomena can be understood in terms of affordances. For example, a postbox affords the possibility to post a letter to a friend, or a composition by Bach affords to be played or listened to (Ibid 120).

It is instructive to briefly contrast Gibson's notion of affordance and the ecological approach to psychology in which it is embedded to the paradigm of cognitivism in cognitive science. In cognitivism, it is posited that cognition arises as a consequence of the production and manipulation of representations, processes somehow realized in the human brain (cf. Kiverstein and Rietveld 2018). From a cognitivist perspective, the cognizer is understood a recipient of environmental stimuli, which are processed and manipulated in the brain, eventually giving rise to intelligent behavior. The fact that we seem to perceive possibilities for action directly, then, can be explained with reference to the rapid way in which stimuli are processed by the brain. On Gibson's account, in contrast, the environment is taken to be relative to our bodily skills, appearing first and foremost as a ground for action: "(affordances) seem to be perceived directly because they are perceived directly" [Gibson 2015 (1979), 131].

Perception of affordances are not stable across different animals but have to be measured "relative to the animal. They are unique for that animal. They are not just abstract physical properties" (Ibid. 120). For example, whereas a standard desk affords the possibility to read to for an adult human of a certain shape, it does not do so for a child for which the desk is too high to read, but instead affords to 
hide. Similarly, for other species of animals, a desk might primarily afford to find shelter. It is thus relative to a given animal that the different substances in the environment have meaning.

The different ways in which different animals perceive affordances is explained by Gibson through the concept of ecological niche. It is because different animals have different ecological niches that they perceive different affordances. A niche "refers more to how an animal lives than to where it lives" (Ibid. 120), and can be understood as "a setting of environmental features that are suitable for an animal, into which it fits metaphorically" (Ibid 121). Gibson suggests that a niche is best understood as a set of affordances. For example, in the niche of a species of birds, the air affords flying, trees afford finding shelter against other animals that afford being-eaten by, or certain twigs afford building a nest. In the niche of the human being, the air does not afford flying, but does afford breathing, trees afford being chopped down and be used to build a house that affords being protected against the cold, and so on. The affordances perceived within a given niche are neither the result of the practices of valuing of a given animal or subject, nor are values that are intrinsic properties of the objects in the environment; rather, there is a mutual reciprocity between animal and environment (cf. Blok 2014). ${ }^{3}$ As Gibson puts it, "[a]n affordance points both ways, to the environment and to the observer" [Gibson 2015 (1979), 121]. It is because certain species fit into certain environments that it is possible for ecological niches to emerge, which, in turn, make it possible for the animal to perceive specific affordances.

The ecological niche does not offer the same affordances everywhere. According to Gibson, different affordances are perceived in what he calls the different places in an animal's niche. For Gibson, a place does not denote a specific spatiotemporal location, but instead is a region within an ecological niche that has no clear or definite boundaries [Gibson 2015 (1979), 127]. Places are characterized by having a relative stability in that certain resources, hazards, and activities can be found regularly in them, such that the animal perceives particular affordances relative to these regularities. For example, there are places where animals finds shelter such as their homes or nests, and which afford things like mating, reading a book, or resting. This place is very different from a pool that affords drinking and wishing, but where

\footnotetext{
3 Acknowledging this reciprocity has consequences for the use of the concept of "affordances" in design. It indicates that affordances are not "things" that can be designed "into" artifacts (cf. Norman 2015,3 ), but instead arise in the relation between an organism (e.g., a human being) and an artifact. As will become clear throughout this paper, these relations are shaped by the form of life in which human beings are embedded.
}

also predators might lurk. The affordances that are perceived and solicit action thus differ at different places.

Heft (2001, 252-261, 2007) further specifies Gibson's notions of "place" to the human environment live by introducing the notion of behavior setting, and intends to capture the distinct social nature of some places that humans attend. According to Heft, the human environment is full of places in which certain social possibilities regularly and predictably take place, such as coffee bars, courtrooms, shops, tennis courts, etc. Drawing on earlier work in ecological psychology (e.g., Barker and Schoggen 1973), he understands places in the human environment as behavior settings in which specific forms of collective human action occur. How a behavior setting concretely manifests depends on both the dynamic relationship between different individuals, as well as the inanimate features of the environment that support the intended activity. For example, playing a game of football requires the presence of a group of willing and sufficiently informed individuals, as well as a football pitch with goals. At such places, particular affordances emerge such as the football's being kick-able, an attacker being tackle-able, etc. As Heft puts it, "the affordances of a place for an individual derive from the dynamic, joint interrelationships among the participants and milieu" $(2007,98)$.

What is gained by introducing these Gibsonian concepts for our understanding of the multistability of technologies? First, it can be noted that technologies can be understood as offering specific affordances (Klenk 2020), and that they do so relative to a given animal with a specific ecological niche that constrains possibilities of use: a desk affords writing to some adult humans, and affords shelter to other animals (e.g., rats or small kids). Hence, the specific stability that a technology offers is relative to what it affords to a given animal. Second, since animals perceive different affordances at different places or behavior settings, specific stabilities of technologies are relative to the specific places in which they are used. For example, when one is learning how to do carpentry, a specific behavior setting is constituted, in which a hammer is primarily perceived as affording to help the construction of say a table. In another behavior setting, such as an extreme fighting club, however, a hammer is likely to solicit rather different affordances. Accordingly, the specific behavior setting in which a technology is integrated put constraints on-but not exclusively determines-its stable usages.

In many human interactions, it requires to perceive specific affordances to be able to inhabit into specific behavior settings - to know the rules of the game as it were. Similarly, what is the dominant stability of a technology in a given setting is also not something that can automatically be taken for granted. Understanding how this process takes place requires an understanding of the individual's acquaintance with the 
normativities present in a given behavior setting. This will be the topic of the next section.

\section{Forms of life and the normativity of practices}

More recent interpretations of Gibson's affordance theory use as a starting-point the idea that the environment is best understood as a "rich landscape of affordances" in which organisms (human beings amongst them) are always already immersed (Rietveld and Kiverstein 2014). In this section, I show how these interpretations help explaining that affordances are socially situated, which further explains why certain stabilities of technology use are likely to arise. Following Gibson, such interpretations define affordances as possibilities for action that animals perceive in the environment. For example, a cup of coffee might afford drinking, another human being might afford having a conversation with, or a flat surface might afford cycling. Given the many affordances present in an environment, we cannot act upon all of them at the same time: for example, I cannot at the same time use the affordance of my computer to type this text and the affordance of the pencil lying next to me to write a poem.

As was explained in the previous section, different affordances are perceived in different places or behavior settings. This indicates that the perception of certain affordances in these cases is selective as well: one perceives particular affordances relative to the particularities of the setting or practice one is embedded in. Rietveld and Kiverstein have suggested that this selective perception is well captured by the term-borrowed from Wittgenstein-form of life: the "patterns in (an animal's) behavior, i.e., (its) relatively stable and regular ways of doing things" (Rietveld and Kiverstein 2014, 328). In the case of human beings, such stabilities not only have a biological origin, but are also "manifest in the normative behaviors and customs of our communities" (Ibid. 328-29): they find their ground in our being embedded in a specific form of life. In other words, the number of affordances appearing as relevant to act upon by the human being are constraint by the norms and customs of both the material structure of the environment and the norms and customs constituting what would be "adequate action" in this environment. That is, in the context of the human animal, in many occasions, specific socio-political factors are present. These factors are part of specific forms of life that constitute specific landscapes of affordances that can be perceived and might solicit action. Hence, the concept of "form of life" is explanatory for why human beings are capable of recognizing behavior settings and might act within those in a way proper to them.
Alberto Romele gives a good example of how socio-political norms in a particular form of life shape which affordances are perceived. Reflecting on Latour's (1994) famous example of the speed bump that allegedly delegates moral behaviors to nonhumans by making drivers slow down, he notes that there must be law enforcement procedures and norms concerning traffic in place for speedbumps to work as expected (i.e., as indeed making drivers slow down). Without the presence of these norms and procedures, someone could simply get out of the car and make the speed bump disappear (Romele 2020, 10). Apparently, certain normativities are already at work within traffic that prevent drivers from removing the speed bump, or engage in collective work to make speed bumps disappear systematically. ${ }^{4}$ Relative to these normativities, the speed bump tends to solicit a rather specific affordance; namely the affordance to slow down.

As the above example already indicates, the term "form of life" does not refer to the human being as a species, but instead to the human being as situated in a certain practice. For example, being a soccer player can be considered a form of life with certain customs and norms, while being an academic can be considered another form of life with other customs and norms. And yet another form of life would be the car driver in Latour's example. These different situations each bear different normativities in the sense that individuals are able to distinguish correct from incorrect, better from worse, or adequate from inadequate within them (Rietveld and Kiverstein 2014, 332). As human beings we participate in many different forms of life that might have overlapping normativities. In order to be able to participate skillfully in a form of life, a human being must therefore be selectively responsive to available affordances, making that the environment does not appear as a meaningless lump, but instead as making certain affordances stand out, such that these can be unreflectively acted upon.

The notion of "normativities" can be further unpacked with reference to the concept "tendency towards optimal grip". Bruineberg and Rietveld (2014) use this concept to signify how skilled individuals acting in a familiar environment act in order to improve their grip on a situation through

\footnotetext{
${ }^{4}$ Romele offers a different explanatory framework for the stability of speed bumps that is not informed by affordance theory, but by the work of Pierre Bourdieu (Romele 2020). A systematic comparison between these two approaches and the different explanations of multistability that they might give is beyond the scope of this paper.
} 
an unreflective experience of a deviation of an optimum. ${ }^{5}$ They quote Merleau-Ponty to illustrate this:

For each object, just as for each painting in an art gallery, there is an optimal distance from which it asks to be seen - an orientation through which it presents more of itself - beneath or beyond which we merely have a confused perception due to excess or lack. Hence, we tend toward the maximum of visibility and we seek, just as when using a microscope, a better focus point, which is obtained through a certain equilibrium between the interior and the exterior horizons (Merleau-Ponty 2012, 315-316).

According to Merleau-Ponty, then, when viewing a painting, we search for its optimal view and act selectively upon affordances in striving for this optimum. Bruineberg and Rietveld extend this idea to situations beyond the perception of an artwork. For example, also when observing microorganisms through a microscope, the skilled microscopist acts upon the affordances of the microscope (that e.g., affords focusing) to get a more optimal view of the microorganism under study. In such an action, other affordances offered by the environment (for example, the calendar in the laboratory that affords being written on) disappear from view since they are irrelevant for improving the microscopist's grip on her situation. This is not to say that optimal grip on a situation is obtained when it is perceived what the object (e.g., a micro-organism) "really" looks like (as if the "reality" of an object works as a magnet on human experience), but rather that the experienced suboptimum"a tension that oscillates around a norm" (Ibid 316)—might disappear, or replaced by another experienced sub-optimum. In other words, the "optimal" in "tendency towards optimal grip" refers to the norm present in the form of life of microscopists of what counts as a good or adequate observation of a micro-organism. This indicates that a specific form of life offers a structure of concern to the people situated in a particular practice, which makes that specific affordances are soliciting action.

Being skilled in a certain form of life (e.g., the microscopist's) makes that a human being has a tendency towards optimal grip in a given situation, such that certain affordances are perceived as relevant possibilities for action. We

\footnotetext{
${ }^{5}$ Robert Rosenberger has recently proposed the concept of "relational strategy" to explain how users are enabled to pick up a technology in terms of a particular stability. He defines this term as "the set of bodily comportments, pre-perceptive expectations, understandings, and habits that enable one to use a technology in a particular way" $(2017,235)$. The present account of why a specific stability can become dominant helps explaining why a specific relational strategy is likely to be adopted; namely through the perception of a given affordance that aligns with the normativities of a given practice.
}

can thus say that which affordances appear as solicitations for actions depend on the normativity of the specific form of life the human being is immersed in (e.g., Van Dijk and Rietveld 2017). However, there is a distinction to be made between the landscape of affordances that might solicit action to a form of life in general (e.g., microscopists) and the field of relevant affordances appearing as solicitations for actions to a concrete individual (Rietveld et al. 2018, 57).

Although individuals might participate quite often in a specific form of life, they never completely coincide with it. Hence, the field of relevant affordances that solicit actions for a concrete individual must not be equated with the landscape of affordances present in a form of life; the individual might anticipate on affordances present in another form of life, or might not be aware of all the affordances present in a form of life, or might perceive affordances due to other concerns. For example, a skilled microscopist might be hungry when engaging in an observation practice, such that the (not visibly present) canteen is part of her field of affordances, drumming on a table might be part of it due to her being engaged in the music she hears on the radio playing in the laboratory. In other words, the field of affordances constituted for an individual does never completely coincide with the landscapes of affordances of the form of life in which she is immersed.

This non-coincidence implies that which affordances solicit action is not fully determined by the normativities present in a form of life. First of all, it is always in principle possible to engage in transgressive behavior, thereby (deliberately) neglecting the normativities within a form of life. Second, the environment might solicit certain affordances that conflict with the normativities within a form of life. Aagaard's recent study of laptop use in an educational setting is a good example of this. In this study, Aagaard shows - on the basis of interviews with students-that laptops in classrooms solicit affordances (e.g., browsing, frequenting social media) that disturb the learning process and lead to digital distraction. Students express that they find themselves attending websites of which they know that they are counter-productive to education without feeling that they have deliberately chosen to do so (Aagaard 2018).

Now, are these instances counter-examples against the idea that normativities in a form of life put constraints on which affordances solicit action? With regard to the case of transgression, it can be noted that the idea of transgressing normativity is grounded in the acknowledgment of this very normativity. However, in the case of transgression there seems to be a discrepancy between the field of affordances of a given individual and the landscape of affordances present in a form of life. The case of digital distraction shows that the affordances that solicit actions are never fully determined by the normativities present in a form of life. Relating to specific technologies (such as laptops in a classroom setting) 
might help constituting a field of affordances in which affordances relevant to the form of life participated in remain unperceived. However, the very fact that Aagaard's interviewees remain orienting to the norms present in a particular form of life reveals the relative stability of a landscape of affordances, even though that not all affordances present in it are perceived at every moment in time. In conjunction, these potential counter-examples help revealing that acknowledging the situated nature of affordances simultaneously implies to acknowledge that forms of life do not govern which affordances solicit action.

\section{Specifying the situatedness of affordances}

The central question guiding this paper was why technologies appear as multistable, instead of "just" stable or "just" instable. In this section, I make explicit how the concepts introduced in the previous sections help answering this question. I do so through a comparative discussion of the account proposed above and two recent attempts to mobilize affordance theory as an argument against the value-neutrality thesis by Michael Klenk and Fabio Tollon. I suggest that the account proposed above importantly augments these accounts by highlighting the situated nature of affordances and showing how the normativities within certain forms of life puts constraints on the actions that affordances solicit.

On Klenk's account, technological artifacts embody affordances because they have certain objective responsedependent properties: "artefact $\mathrm{x}$ has affordance $\mathrm{A}$ in virtue of its physical properties relative to a user's potential behavioral response or ability" (Klenk 2020, 14). For example, a screwdriver affords screwing in virtue of both its shape and the user's ability to recognize this affordance. Here, it is important to point out that for Klenk, these properties exist objectively (i.e., independently of being picked up by someone). Hence, regardless of the affordance of screwing is perceived in a given screwdriver, the artifact maintains the response-dependent properties that make it to afford screwing under the right circumstances.

Klenk convincingly argues that artifacts indeed embody affordances that are response-dependent properties, yet his account is not designed for clarifying why certain technologies solicit certain actions, why certain technology usages stabilize, or why technological artifacts allow having multiple stabilities. ${ }^{6}$ It is at this point that Klenk's account is criticized by Tollon who maintains that it insufficiently explains

\footnotetext{
${ }^{6}$ I leave aside here how Klenk eventually argues that responsedependent properties can be understood as values, as my concern is not primarily with providing an alternative for the value-neutrality thesis, but with offering an account of the multistability of technologies.
}

why affordances make certain actions more likely than others (Tollon 2021, 8). Tollon proposes two steps in this direction by urging to pay attention to (1) the meaningfulness of affordances, and (2) the force of affordances.

With regard to the former, he gives the following example: whether a glass of water is perceived as affording to drink is dependent on how thirsty someone is, which suggests that how an artifact solicits specific actions is dependent on its relevance for our concerns (Tollon 2021, 7). Tollon accordingly argues that, regardless of whether affordances are indeed objective properties of artifacts, their meaningfulness depends on the specific concerns of the user of an artifact (Ibid 8). Concerning the latter, he holds that it is possible to grade affordances in terms of them being "demanding" or "inviting". He proposes that the force of the affordances in a given technological artifact can be graded with reference to their design. On his view, some technologies have a "demanding" character with regard to the actions they solicit, whereas other have an "inviting" character in doing so (Ibid 9). He illustrates this with the example of the different ways in which an AK-47 and a handgun are designed, and suggests that an AK-47 demands to be lethal due to its design, whereas a handgun allegedly only invites being used as a lethal weapon in specific circumstances, such as when it is used as a means for self-defense. On Tollon's account, specific stabilities of technology use are thus constituted in virtue of the technology's meaningfulness for the subject, or the force that it exhibits.

Klenk and Tollon each tend to highlight specific aspects of the human subject or the environment for explaining why specific affordances solicit actions. On the one hand, Klenk tends to conceive of affordances as objective properties of the environment (e.g., a technological artifact) that exist independently of them being perceived, which Tollon further specifies in terms of the different forces that technological artifacts embody. On the other hand, Tollon's notion of "meaningful affordances" suggests that specific solicitations for actions originate in the subject's specific concerns through which certain affordances are more likely to be perceived. However, as became clear in my discussion of Gibson's work and of recent work that link affordances to the normativities present in certain forms of life, it is in the relation between (human) animal and specific places or behavior settings that affordances solicit specific actions.

Let me specify how this account allows for developing a more situated way of understanding how certain technological solicit affordances and how it helps accounting for multistability.

First, when not considering technologies in isolation, but instead as part of a landscape of affordances constituted within a form of life, it becomes clear that what a technology affords is relative to the normativity and customs of the landscape in which it figures. This helps explaining 
why organisms perceives specific affordances in different behavior settings: since human beings experience a tendency towards optimal grip on a given situation whilst being immersed in a form of life, the likelihood increases that only particular stabilities of technologies use are perceived as affordances that solicit actions. For example, the normativity of the form of life of an academic puts constraints on the likelihood of enacting the table's stability of allowing to stage a fencing match, because this might not be perceived as a relevant affordance for improving one's grip on the situation. Instead, the affordance of the table to carry a laptop that affords typing, or the affordance of sleeping on the table might reasonably be expected to stand out in the form of life of an academic as affordances soliciting action. Understanding affordances relative to forms of life allows understanding novel technologies in terms of their (dis) alignment with certain normativities. As we saw in the previous section, such a perspective allows critically comparing the affordances solicited by a particular artifact (e.g., laptop use in a classroom setting) vis-à-vis the eventual purpose of a particular behavior setting.

Second, since norms and customs are different in different forms of life, it makes perfect sense to think of the table's affordance to stage a fencing match within the form of life of the fencer. In other words, by understanding the environment as a landscape of affordances relative to a form of life, it becomes clear how the environment not only puts constraints, but also offers specific opportunities through which stabilities of technologies can be enacted as relevant affordances. This is explanatory of why technologies are capable of fitting multiple contexts.

Finally, the distinction between a field of relevant affordances and a rich landscape of affordances makes clear why different stabilities of a technology can be enacted within a certain form of life. Moving back to the affordances of a table in the form of life of an academic, this distinction makes clear that for someone who had a really bad night of sleep, the table's stability of allowing to sleep on becomes an affordance soliciting action, while for someone who wants to email a colleague, the table's affordance of using her laptop is one soliciting action. The analysis conducted in this paper shows that certain stable usages of a technology are relative both to how the landscape of affordances and to how the field of relevant affordances is constituted. At the same time, the analysis of how technologies solicit certain actions conducted in this paper points to their crucial role in the constitution of a particular field of relevant affordances-a role that is not significantly emphasized in the literature on affordances. Let me briefly summarize the implications for the account of multistability sketched in this paper for postphenomenological research. When it is recognized that different stable usages of a technology are constituted in relation to the normativities present in a form of life, it seems that the identified stabilities cease to be merely relative to the point of view-or pivot point—of a given analyst (cf. Whyte 2015). ${ }^{7}$ Rather, it allows to legitimate a specific pivot point with reference to the normativities present in a specific form of life, comparing specific stable ways of technology use against these normativities, as well as critically scrutinizing existing normativities in light of certain stable usages.

\section{Conclusion}

In this paper, a proposal was made to account for the multistability of technologies (i.e., their being able to be put to use for a variety of different purposes, to fit into multiple different contexts, or to have a different meaning for different people). This was done in four steps: first, I reviewed different examples of discussions on multistability in the postphenomenological literature, and showed the variety of ways in which the concept is used. On the basis of this review, I argued that, while there are several clear examples of the multistability of technologies, an account explaining the phenomenon of multistability is absent. Second, I introduced the Gibsonian concepts of "affordance," "niche," and "place" and Hefts concept of "behavior setting" to explain how the environment in which technologies are embedded puts constraints on how they are used, thereby giving rise to specific stabilities. Third, by suggesting that "the environment" can be understood as a rich landscape of affordances on which human being strive to have an optimal grip, I showed how the form of life within which technologies are immersed influences the affordances a technology is perceived to offer. Fourth, I compared the approach developed in this paper with recent accounts of the "affordance character" of technologies, and suggested that approach presented in this paper allows for developing a more situated way of understanding how certain technological solicit affordances and how certain stable usages might arise out of this.

What has remained unaddressed thus far in this paper, but what is a central concern in the philosophy of technology is the potentially disruptive nature of technologies: their possibility to help establishing new normativities, or change existing value structures for better or worse. In postphenomenology, the concept of "technological mediation" seems central in understanding technologies as a source for change. Verbeek describes this notion as follows: "(Technological) mediation consists in a mutual constitution of subject and object [...]. It shapes the mutual relation in which both subject and object are concretely constituted" (130). Such an understanding stresses that neither human beings nor

\footnotetext{
7 This is of course not to imply that recognizing certain normativities in a form of life allows to remove the analyst's point of view.
} 
technologies have certain essential features, but rather that in the relation between them (e.g., when a technology is put to use), both poles are constituted in a specific way. Novel technologies, then, potentially constitute both subject and object anew in the process of mediation. And much earlier, Gilbert Simondon argued that technological objects constitute new associated milieus that need to be retained for technological objects to function [Simondon 2017 (1958): see also Feenberg 2017]. Now, what is suggested by the affordance-based account of multistability developed in this paper is that the forms of life in which they are embedded puts limits on the allegedly disruptive potential of technologies. The specific focus on the situated character of affordances identified in this paper might be of help when investigating how different technologies attain different stabilities in different situations. This opens up an interesting avenue for future research focusing on how disruptive technologies help constituting new forms of life in which specific normativities manifest, and how these relate to the normativities present in existing forms of life.

Acknowledgements I wish to thank the editors of AI \& Society, as well as the anonymous reviewers for their constructive feedback and suggestion. Furthermore, I would like to thank Vincent Blok for commenting on an earlier version of this paper.

Open Access This article is licensed under a Creative Commons Attribution 4.0 International License, which permits use, sharing, adaptation, distribution and reproduction in any medium or format, as long as you give appropriate credit to the original author(s) and the source, provide a link to the Creative Commons licence, and indicate if changes were made. The images or other third party material in this article are included in the article's Creative Commons licence, unless indicated otherwise in a credit line to the material. If material is not included in the article's Creative Commons licence and your intended use is not permitted by statutory regulation or exceeds the permitted use, you will need to obtain permission directly from the copyright holder. To view a copy of this licence, visit http://creativecommons.org/licenses/by/4.0/.

\section{References}

Aagaard J (2018) Magnetic and multistable: reinterpreting the affordances of educational technology. Int J Educ Technol High Educ. https://doi.org/10.1186/s41239-017-0088-4

Aagaard J (2021) 4E cognition and the dogma of harmony. Philos Psyc 34:166-181. https://doi.org/10.1080/09515089.2020.1845640

Aydin C, Woge MH, Verbeek PP (2019) Technological environmentality: conceptualizing technology as a mediating milieu. Philos Technol 32:321-338. https://doi.org/10.1007/s13347-018-0309-3

Barker RG, Schoggen P (1973) Qualities of community life: Methods of measuring environment and behavior applied to an American and English town. Jossey-Bass, San Francisco

Blok V (2014) Being-in-the-world as being-in-nature: An ecological perspective on Being and Time. Studiae Phaenomenologica 14:215-235. https://doi.org/10.5840/studphaen20141411
Bruineberg J, Rietveld E (2014) Self-organization, free energy minimization, and optimal grip on a field of affordances. Front Hum Neurosci 8:599. https://doi.org/10.3389/fnhum.2014.00599

de Boer B (2021) How scientific instruments speak: Postphenomenology and technological mediations in neuroscientific practice. Lexington Books, Lanham

Feenberg A (2017) Technosystem: The social life of reason. Harvard University Press, Cambridge

Forss A (2012) Cells and the (imaginary) patient: The multistable practitioner-technology-cell interface in the cytology laboratory. Med Health Care Philos 15:295-308. https://doi.org/10.1007/ s11019-011-9325-0

Gibson J (2015) [1979]) The ecological approach to visual perception. Psychology Press, New York

Heft H (2001) Ecological psychology in context: James Gibson, Roger Barker, and the legacy of William James's radical empiricism. Lawrence Publishers, London

Heft $\mathrm{H}$ (2007) The social constitution of perceiver-environment reciprocity. Ecolog Psychol 19:85-105. https://doi.org/10.1080/ 10407410701331934

Ihde D (1990) Technology and the lifeworld: From garden to earth. Indiana University Press, Indianapolis

Ihde D (1998) Expanding hermeneutics: Visualism in science. Northwestern University Press, Evanston

Ihde D (2009) Postphenomenology and technoscience: The Peking lectures. SUNY Press, New York

Ihde D (2016) Husserl's missing technologies. Fordham University Press, New York

Kiverstein JD, Rietveld E (2018) Reconceiving representation-hungry Cognition: an ecological-enactive proposal. Adap Behav 26:147-163. https://doi.org/10.1177/1059712318772778

Klenk M (2020) How do technological artefacts embody moral values? Philos Technol. https://doi.org/10.1007/ s13347-020-00401-y

Latour B (1994) On technological mediation. Comm Knowl 3:29-64

Lemmens P, Blok V, Zwier J (2017) Toward a terrestrial turn in philosophy of technology. Techné 21:114-126. https://doi.org/10. 5840/techne2017212/363

Merleau-Ponty M (2012) Phenomenology of perception trsl. DA Landes, Routledge, London

Norman D (2015) Affordances: commentary on the special issue of AI EDAM. AIEDAM. https://doi.org/10.1017/S0890060415000232

Rietveld E, Kiverstein J (2014) A rich landscape of affordances. Ecolog Psychol 26:325-352. https://doi.org/10.1080/10407413.2014. 958035

Rietveld E, Denys D, van Westen M (2018) Ecological-enactive cognition as engaging with a field of relevant affordances: The skilled intentionality framework. In: Newen A, de Bruin L, Gallagher S (eds) The oxford handbook of 4E cognition. Oxford University Press, Oxford, pp 41-70

Romele A (2020) Technological capital: Bourdieu, postphenomenology, and the philosophy of technology beyond the empirical turn. Philos Technol. https://doi.org/10.1007/s13347-020-00398-4

Rosenberger R (2009) The sudden experience of the computer. AI \& Soc 24:173-180. https://doi.org/10.1007/s00146-009-0190-9

Rosenberger R (2014) Multistability and the agency of mundane artifacts: from speed bumps to subway benches. Hum Stud 37:369392. https://doi.org/10.1007/s10746-014-9317-1

Rosenberger R (2016) Husserl's missing multistability. Techné 20:153167. https://doi.org/10.5840/techne20168356

Rosenberger R (2017) On the hermeneutics of everyday things: or, the philosophy of fire hydrants. AI \& Soc 32:233-241. https://doi.org/ 10.1007/s00146-016-0674-3

Rosenberger R (2020a) "But, that's not phenomenology!”: a phenomenology of discriminatory technologies. Techné 24:83-113. https:// doi.org/10.5840/techne2020210117 
Rosenberger R (2020b) On variational cross-examination: a method for postphenomenological multistability. AI \& Soc. https://doi. org/10.1007/s00146-020-01050-7

Rosenberger R, Verbeek PP (2015) A field guide to postphenomenology. In: Rosenberger R, Verbeek PP (eds) Postphenomenological investigations: essays on human-technology relations. Lexington Books, London, pp 9-41

Rosenfeld AM (2015) Mediating multiplicity: Brain-dead bodies and organ transplant protocols. In: Rosenberger R, Verbeek PP (eds) Postphenomenological investigations: essays on human-technology relations. Lexington Books, London, pp 203-215

Simondon G (2017) [1958]) on the mode of existence of technical objects (trsl Malaspina C, Rogove J). Univocal Publishing, Minneapolis

Tollon F (2021) Artifacts and affordances: from designed properties to possibilities for action. AI \& Soc. https://doi.org/10.1007/ s00146-021-01155-7

van Dijk L, Rietveld E (2017) Foregrounding sociomaterial practices in our understanding of affordances: the skilled intentionality framework. Front Psychol 7:1969. https://doi.org/10.3389/fpsyg. 2016.01969
Verbeek PP (2005) What things do: philosophical reflections on technology, agency, and design. University of Pennsylvania Press, Pennsylvania

Wellner G (2020) The multiplicity of multistabilities: Turning multistability into a multistable Concept. In: Miller G, Shew A (eds) Reimagining philosophy of technology, reinventing Ihde. Springer, Dordrecht, pp 105-122

Whyte KP (2015) What is multistability? A theory of the keystone concept of postphenomenological research. In: Crease RP, Friis JKBO (eds) Technoscience and postphenomenology: The Manhattan papers. Lexington Books , New York, pp 69-81

Zheng EL (2021) Interpreting fitness: self-tracking with fitness apps through a postphenomenological lens. AI \& Soc. https://doi.org/ $10.1007 / \mathrm{s} 00146-021-01146-8$

Publisher's Note Springer Nature remains neutral with regard to jurisdictional claims in published maps and institutional affiliations. 